Broad areas workers found helpful were good communication from managers, flexibility of duties on return to work (including temporary non-clinical roles), sympathetic support from colleagues and access to counselling support from organisations.

Broad areas workers found unhelpful were an absence of meetings and communication from managers, rigid compassionate leave policies and perceived lack of recognition of their loss.

Conclusions There was variation between individuals about factors they perceived to be helpful. This suggests a rigid approach universally applied is unlikely to support all employees. In our opinion, early sympathetic meetings with management offering temporary adjustments to roles (and/or hours), sensitive informing of colleagues and signposting to counselling options is likely to have a positive impact on staff wellbeing.

\section{MAPPING OF BEREAVEMENT SERVICES ACROSS THE NORTH EAST OF ENGLAND - A SURVEY OF GENERAL PRACTITIONERS REFERRING PRACTICE}

D Wakefield, F Dewhurst, J Brown, E Kavanagh, R Kiltie, F McCormick, J Pickard, G Rowley, K Waterfield, L Woods, A Clark. Palliative Medicine Registrars, Health Education North East (HENE)

\subsection{6/bmjspcare-2019-ASP.25}

Background Recent national guidelines have identified the importance of bereavement support. However, evidence suggests that bereavement services are provided inconsistently. We aimed to map bereavement services used by GPs across the North-East-of-England to identify inequalities.

Method An electronic bereavement service questionnaire was produced through consultation with Northern England Clinical Networks and CCG end-of-life-care leads and was then reviewed by a local GP focus group. The questionnaire was then distributed to CCG EOLC leads who cascaded it to all 392 practices in the North-east of England. A Reminder email was sent after 4 weeks.

Results 85 (22\%) GP practices completed the survey. Only $43.5 \%$ and $9.4 \%$ of practices reported that they had a bereavement policy and that the majority of their GPs' had had bereavement training respectively. $21 \%$ reported that they would not refer patients anywhere for bereavement support. The remaining 79\% listed 18 services that they refer to, most commonly; hospices(21\%), CRUSE(17\%), MIND(15\%), Macmillan(10\%) and their own in-house counsellor(10\%) and 25 services that they recommend for self-referral, CRUSE(65\%), talking therapy(16\%), hospice(14\%), Improved Access to Psychological Therapies(11\%).

Conclusion A wide range of bereavement services are used across the region. They mainly depended on charitable funding. One fifth of responding GP practices reported that they would not refer patients for bereavement support. This was associated with comments including "local services have been decommissioned" and "not aware of any services to refer to". This highlights the wide variation in use and availability of bereavement services across the region, and the problems of service withdrawal, lack of funding and lack of clarity on who is responsible for bereavement support. This will be invaluable in providing evidence to commission future bereavement services.

\section{INNOVATIVE FOUR STEP BEREAVEMENT SERVICE AT A TERTIARY CANCER CENTRE}

Ann Griffiths, Alison Coackley, Malcolm Cooper, Amanda Watson, Sinead Benson, Claire Cadwallader, Dan Monnery, Julian Hampton-Matthews. The Clatterbridge Cancer Centre

10.1136/bmjspcare-2019-ASP.26

Background Bereavement is defined as the state of a loss when someone close to you has died. It is important that people closely affected by a death are communicated with in a sensitive and timely manner and that those at risk of pathological bereavement reactions are identified and supported. At a tertiary cancer centre it was recognised that families need time and support soon after the death of their loved one.

Aim To deliver a 'day after death' service providing personalised bereavement support to families/carers and learn lessons about care by discussing their experiences.

Methods At our tertiary cancer centre we implemented an innovative 4 step approach to supporting bereaved families and carers:

1. Comprehensive documentation including a bereavement risk assessment at the time of death.

2. Innovative 'day after death' service.

3. Post bereavement contact if accepted.

4. Face to face follow up where required.

The bereaved families/carers meet with a senior member of the Nursing Team who knew the patient on the next working day. They meet in a private room away from the wards and discuss how they are coping with their loss and listen to any questions/concerns they may have. The relevant paperwork is then provided. This also provides the opportunity to follow up the bereavement risk assessment undertaken by the ward staff.

Following the meeting a reports is shared with the Director of Nursing and discussed at the Trust Executive meeting.

Results There have been 84 deaths within the tertiary cancer centre in the last 12 months. All bereaved families/carers have received the day after death service. This has enabled us to provide comprehensive and personalised bereavement care. It also enables us to identify those people likely to have complex bereavement and signpost to local specialist support services. Conclusions We have successfully implemented a 4 step innovative service delivering personalised bereavement care.

\section{Caregivers and the Family | Posters $4-7$}

\section{TYPE, INTENSITY AND QUALITY OF INFORMATION GIVEN BY PHYSICIANS DURING THE CANCER JOURNEY OF PALESTINIAN CHILDREN WITH LEUKAEMIA: BETWEEN REVELATION AND CONCEALMENT}

Maha Atout, Bernie Carter. Philadelphia University, Edge Hill University

\subsection{6/bmjspcare-2019-ASP.27}

Background Despite the accumulation of evidence that supports the importance of giving parents detailed information, there is less evidence to support the notion that providing 'negative' information has a harmful effect on both parents and children. This study explored the communication of information across the cancer journeys taken by children from 
different perspectives in Palestine. This paper reports on the perceptions of the physicians.

Methods This study used an ethnographic qualitative case study approach. It was conducted in one oncology unit in one Palestinian hospital and used two data collection methods: participant observation and semi-structured interviews.

Results The study generated 70 hours of observation and 35 interviews; physicians $(n=5)$, nurses $(n=11)$, children aged 6$18(n=6)$, mothers $(n=7)$ and grandmothers $(n=6)$. The findings demonstrated that physicians were reasonably open with parents at the diagnosis stage; however, as the child's condition got worse, they concealed negative information to protect parents from emotional suffering. However, despite their tendency to conceal information, they associated revealing information about the child's deterioration to parents as an important act to protect themselves legally. Furthermore, they generally concealed negative information from children. There seemed to be a close link between the type, intensity and quality of information revealed and the stage of the cancer journey (diagnosis, treatment and prognosis).

Conclusions This study of Arab physicians delivering care to children with cancer and their families are positioned at a point in tension where they are reluctant to reveal information about a child's deterioration and the knowledge that by concealing this information they place themselves in a difficult position. Although concealing information may be explained by cultural context, it does leave a communication gap for children and their parents at a very sensitive time in the child's cancer journey.

\section{PUBLIC TRANSPORT AND HOSPICES - DO THEY LINK?}

Caroline Hart, Miriam Rigby, WM Cares. West Midlands Deanery

\subsection{6/bmjspcare-2019-ASP.28}

Background Hospitals tend to be in central locations with good links to public transport including dedicated bus stops etc. This is due to very high numbers of both staff and patients needing 24 hour access. Hospices however tend to be less central, in quieter locations, making them less accessible to those who can't drive; be they patients, their relatives or staff. So how easy are they to get to? And how easy is this information to find?

Method For all the hospices within the West Midlands with an inpatient unit (IPU); we looked at the following: what information was available on their website regarding access via public transport; how to access the IPUs via public transport using 'traveline.org' and Google. Finally, we contacted each hospice to ask if they had any written patient/visitor information regarding getting to the hospice.

Results We identified 12 hospices, and 15 IPUs in total. 5 had a link on their homepage indicating 'how to find us', 2 had information about nearest bus routes,. 3 had information about the nearest train station. When contacting the hospices directly, only 3 hospices had written information available to give to patients and their relatives. We found that the distance from a bus stop to the hospice varied from a 2 to a 15 min walk, and more than half have no or very limited Sunday service.

Conclusions Most of the hospices in the West Midlands region have no information available regarding accessing the site using public transport, and limited transport services especially off peak.
Does this feed in to the inequalities in access to hospice services already seen across socioeconomic groups? In the first instance we hope this will encourage hospices to provide more travel information for patients, but could this also guide service development and future hospice location planning?

\section{THE AGE OF THE CARER HAS AN IMPACT ON THE BURDEN OF CARE EXPERIENCED BY THE CARER}

F Mukhtar, U Raja, S Singh, N Lovell, D Yi, IJ Higginson. King's College London, Cicely Saunders Institute

\subsection{6/bmjspcare-2019-ASP.29}

Context Those caring for people with chronic illnesses report high levels of unmet needs. Carers for patients with chronic illnesses must learn how to adapt with the demand of looking after a patient with a deteriorating condition. This can lead to increased stress due to sacrifices such as less time for socialising/financial difficulty.

Objectives To evaluate whether the age of the carer has impact on the burden experienced from caring for patients. Understanding the effect of caring for patients with chronic breathlessness and its burden would help interpret the results drawn from the main analysis of the OPTBreathe study, which investigated the preference for the breathlessness support service.

Methods Answers to the carer burden inventory (CBI), included in the face to face interviews with carers were analysed by carer's age. Categories of age were generated and answers to CBI items were converted into a total burden score. and synthesised by the scoping review of literature on the carers' wellbeing. relationships within the data and relating it to the results of other studies related to the wellbeing of cares. This includes journals and qualitative studies.

Results 65 carers completed 20 items in the CBI, The average age was 65 and 9 of 65 carers were men. 49/65 stated being either comfortable or coping on their current income, whereas only $10 / 65$ stated in financial difficulty. Average burden score was 18.9: 12.5 in age $<40 ; 16.4$ in $40-49 ; 18.3$ in $50-59$; 20.7 in $60-69 ; 20.3$ in $70-79$ and 17.4 in $80+$. The graphical illustration showed that there was an increasing trend from the $<40$ age range.

Conclusions Though the relationship was not linear the results indicate that there is clear larger burden of care on older carers. Suggestions as to why include increased morbidities in older carers and increased financial burden.

\section{CARERS' REFLECTIONS ON PROVIDING INFORMAL END OF LIFE CARE AND THE POST-CARE PERIOD: A QUALITATIVE STUDY IN SOUTH GREATER MERSEYSIDE}

James Watson, Katherine Jehan. University of Liverpool

\subsection{6/bmjspcare-2019-ASP.30}

Background End of life care need is increasing and will continues to do so. Government policy is for terminal patients to receive care and die in their preferred location. Most terminal patients prefer to receive care and die at home, but lack of palliative care funding places a substantial burden on informal carers. Inequalities exist in end of life care; informal carers 